\title{
In-stent Restenosis. Acute and Long-Term Outcomes after Excimer Laser Coronary Angioplasty
}

\author{
Jorge Bejarano, Edgardo Bermudez, Pedro Diaz, Francesca Gallarello, James R. Margolis
}

Miami Beach - Florida, USA

\begin{abstract}
Objective - With the increased use of intracoronary stents, in-stent restenosis has become a clinically significant drawback in invasive cardiology. We retrospectively assessed the short-and long-term outcomes after excimer laser coronary angioplasty of in-stent restenosis.
\end{abstract}

Methods - Twenty-five patients with 33 incidents of in-stent restenosis treated with excimer laser coronary angioplasty (ELCA) were analyzed. Sixty-six percent were males, mean age of $73 \pm 11$ years, and $83 \%$ were functional class III-IV (NYHA). ELCA was performed using 23 concentric and 10 eccentric catheters with a diameter of 1.6$2.2 \mathrm{~mm}$, followed by balloon angioplasty (PTCA) and ultrasound monitoring. The procedure was performed in the following vessels: left anterior descending artery, 10; left circumflex artery, 8; right coronary artery, 6; left main coronary artery, 2; and venous bypass graft, 7 .

Results - The ELCA was successful in $71 \%$ of the cases, and PTCA was $100 \%$ successful. The diameter of the treated vessels was $3.44 \pm 0.5 \mathrm{~mm}$; the minimal luminal diameter $(M L D)$ increased from $0.30 \mathrm{~mm}$ pre-ECLA to $1.97 \mathrm{~mm}$ post$E L C A$, and to $2.94 m m$ post-PTCA $(p<0.001)$. The percent stenosis was reduced from $91.4 \pm 9.5 \%$ before ECLA to $42.3 \pm 14.9 \%$ after ELCA and to $14.6 \pm 9.3 \%$ after PTCA $(p<0.001)$. Seventeen (68\%) patients were asymptomatic at 6 months and $15(60 \%)$ at 1 year. New restenosis rates were $8 / 33(24.2 \%)$ at 6 months and $9 / 33$ (27.3\%) at 12 months.

Conclusion - ELCA is safe and effective for the treatment of in-stent restenosis. In the present sample, a slight increase in new restenotic lesions between 6 and 12 months was found.

Key-words: laser, restenosis, stents

Correspondência: Jorge Befarano. Miami Heart Institute and Medical Center. Tower Building \# 3424. 4701 N. Meridian AV, Miami Beach. Florida 33140 - USA. Received on $10 / 16 / 98$

Accepted on 4/10/99
Coronary heart disease remains a major cause of morbidity and mortality during the most productive years of life. Currently, a series of therapeutic options are available to manage this condition, which develops as a result of wellknown risk factors. In addition, prevention and medical therapy represent the mainstay in the management of this disease. However, myocardial revascularization with saphenous vein grafts or anastomoses of the internal thoracic arteries and, ultimately, balloon coronary angioplasty, constitute the most recent therapeutic developments in cases where the symptoms persist. Among the new invasive techniques, coronary stenting currently represents the most frequently employed therapeutic modality. The rate of coronary restenosis is higher with stenting than that found with balloon angioplasty ${ }^{1,2}$ as a significant number of patients suffer from in-stent restenosis ${ }^{3-6}$.

The excimer laser (LASER) has been used in the treatment of complex lesions ${ }^{7,8}$; it makes the treatment of in-stent restenosis easier and its results in restenosis are possibly better than those found with balloon angioplasty. We examined this therapeutic modality to define the role of LASER in instent restenosis and to assess the early and late outcomes.

\section{Methods}

The first 25 patients with 33 instances of in-stent restenosis treated with LASER were assessed. Patients with acute myocardial infarction (AMI) or cardiogenic shock were excluded. The clinical features of the patients are summarized in table I. The angiographic analysis was performed with an off-line quantitative method.

After the clinical evaluation, all patients were reassessed in order to identify the angiographic restenosis and the functional class. A successful procedure was defined as the presence of a residual lesion $<50 \%$ in the absence of a new procedure, AMI, emergency surgery or death. The LASER was considered successful when a reduction $\geq 20 \%$ of the initial stenosis was noted; a new angiographic restenosis was defined as the presence of an obstruction $\geq 50 \%$ in the treated site at any time during the follow-up; and AMI was defined as levels of CK and CK-MB above the normal range. 


\begin{tabular}{|c|c|}
\hline \multicolumn{2}{|c|}{$\begin{array}{l}\text { Table I - Clinical features of individuals with in-stent } \\
\text { restenosis }(\%)(n=25)\end{array}$} \\
\hline Age (years) & $73 \pm 11$ \\
\hline Gender (males) & 66 \\
\hline Class III-IV & 83 \\
\hline Previous infarction & 51 \\
\hline Previous heart surgery & 57 \\
\hline Ejection fraction & $48 \pm 9$ \\
\hline Hypercholesterolemia & 89 \\
\hline High blood pressure & 63 \\
\hline Family history & 50 \\
\hline Diabetes mellitus & 31 \\
\hline Smokers & 23 \\
\hline
\end{tabular}

Before the procedure, all patients signed an informed consent, according to the guidelines of the Geneva Convention, the Food and Drug Administration (FDA) and the institution's regulatory committee for research. Twenty-four $(73 \%)$ lesions were treated with a single stent and $9(27 \%)$ with multiple stents. Ultrasound was employed to assess and optimize the final angiographic outcome and additional inflations were performed, when required. With regard to the treated vessels (fig. 1), 20 (61\%) belonged to the left system, $6(18 \%)$ to the right system, and $7(21 \%)$ were saphenous vein bypass grafts.

Laser therapy was performed according to the standard technique ${ }^{7}$. The CVX-300 generator (Spectranetics Corporation, Colorado Springs, Colorado), which works with a wavelength of $308 \mathrm{~nm}$, a laser fluency of $30-60 \mathrm{~mJ} / \mathrm{mm}^{2}$ and a pulse duration of $135 \mathrm{~ms}$ emitted at a repetition rate of $25 \mathrm{~Hz}$, was used as the source of energy. The over-the-wire catheters had a diameter of $1.4 \mathrm{~mm}(\mathrm{n}=2), 1.7 \mathrm{~mm}(\mathrm{n}=16)$, $2.0 \mathrm{~mm}(\mathrm{n}=17)$, and $2.2 \mathrm{~mm}(\mathrm{n}=3)$ to manage lesions in vessels with a diameter of $3.44 \pm 0.5 \mathrm{~mm}$.

\section{Results}

The reference diameter of the vessel (RDV) was $3.44 \pm 0.5 \mathrm{~mm}$. The stents that showed restenosis were: Palmaz-Schatz, 23; GRI, 6; GRII, 1; J \& J Biliar, 3; Wallstent, 4; and AVE, 2 (table II). In regard to the number of stents per each lesion treated, $24(73.0 \%)$ had a single stent placed and $9(27.0 \%)$ had multiple stents placed. In regard to the diameter of the vessels treated, in 25/39 (64.1\%) of them it was $3.5 \mathrm{~mm}$, in $10 / 39(25.6 \%)$ it was $4.0 \mathrm{~mm}$, in $3 / 39(7.7 \%)$ it was $3.0 \mathrm{~mm}$ and in $1 / 39(2.6 \%)$ it was $5 \mathrm{~mm}$. Of the lesions treated,

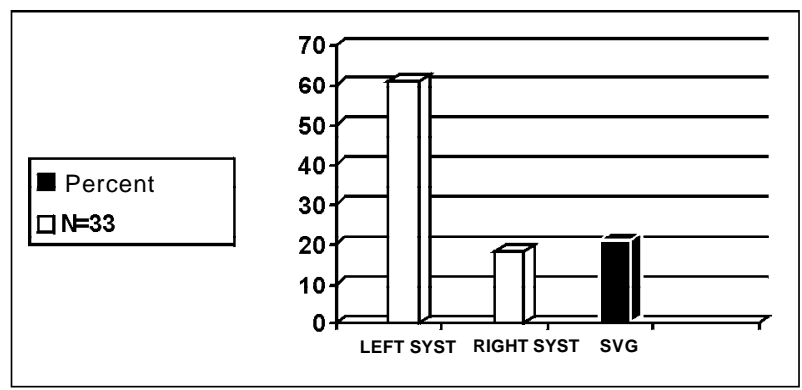

Fig. 1 - Vessels with in-sent restenosis treated with LASER.
$100 \%$ were complex (eccentric and long). The MLD increased from $0.3 \mathrm{~mm}$ before the procedure to $1.97 \mathrm{~mm}$ after the LASER and to $2.94 \mathrm{~mm}$ at the end of the procedure, as assessed by off-line quantitative angiography (fig. 2). The stenosis, which in the beginning was $91.4 \pm 9.5 \%$, was reduced to $42.3 \pm 14.9 \%$ after the LASER and to $14.6 \pm 9.3 \%$ at the end of the procedure (fig. 3). The LASER was $71 \%$ successful and the PTCA, $100 \%$ successful (fig. 4). No acute complications of any kind were noted. At 6 months, 17/25 (68\%) patients were asymptomatic and, at 1 year, 15/25 (60\%) were asymptomatic. Of the 33 lesions, 8 (24\%) required a new procedure at 6 months and $9(27 \%)$ at 1 year.

No differences during the 6-month or 1-year follow-up were noted with regard to emergency surgery and death. None of the patients had an AMI at 6 months or 1 year of

\begin{tabular}{|lc|}
\hline \multicolumn{2}{|c|}{ Table II - Stents with restenosis treated with LASER } \\
\hline Stent & $\#$ \\
\hline Palmaz-Schatz & 23 \\
Gianturco-Roubin I & 7 \\
J \& J Biliar & 3 \\
Wallstent & 4 \\
Microstent & 2 \\
\hline
\end{tabular}

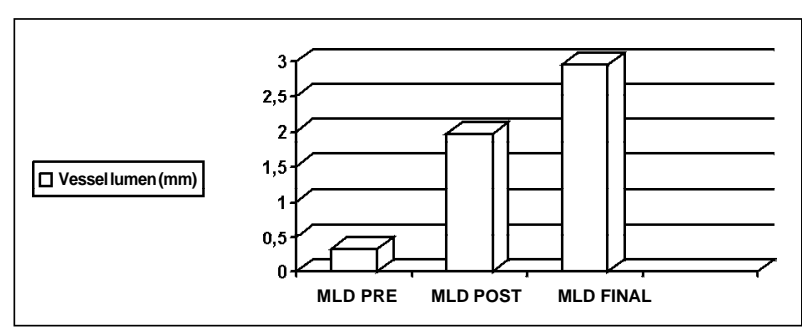

Fig. 2-Minimal luminal diameter (MLD): initial, post-LASER and final (post-balloon).

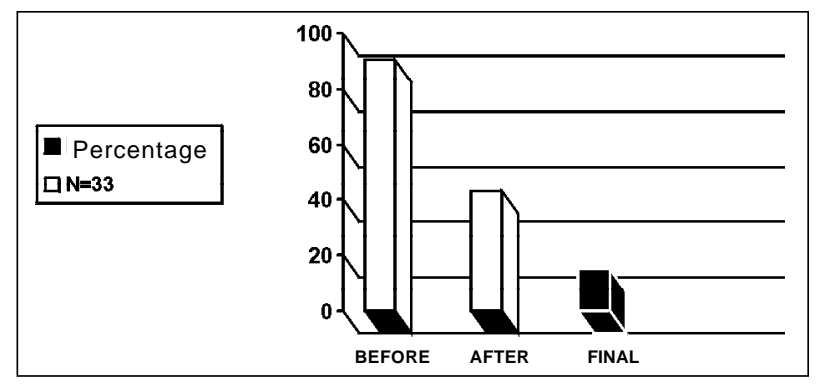

Fig. 3 - Percent restenosis: before, after LASER and final (post-balloon).

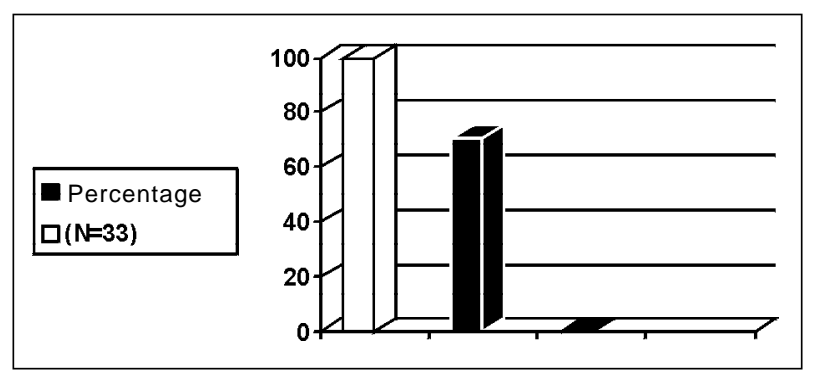

Fig. 4 - Procedure success, LASER success, complications. 


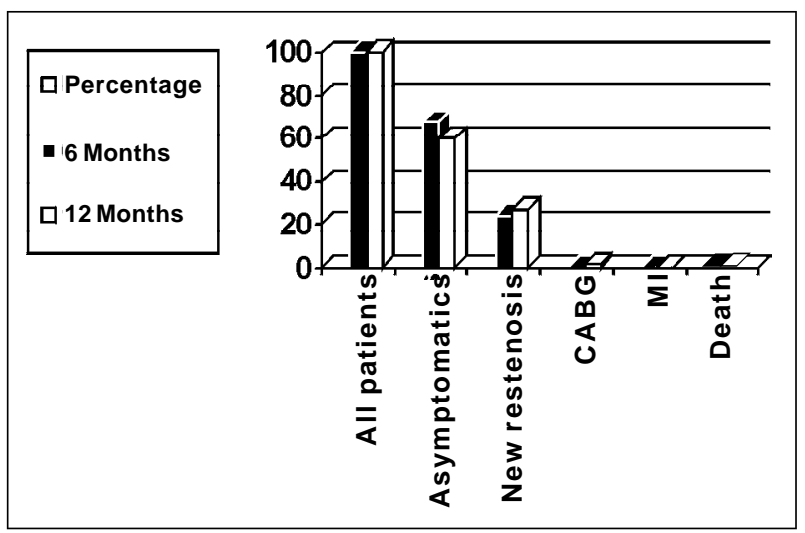

Fig. 5 - Clinical outcome (6 and 12 months) of in-stent restenosis patients treated with LASER $(n=25)$.

follow-up (fig. 5). One (4\%) patient underwent elective heart surgery between 6 and 12 months of follow-up, and another patient (4\%) died of a noncardiac cause in the first 6 months of follow-up.

\section{Discussion}

The present study examines a group of patients of both sexes, most of whom had severe myocardial ischemia. Although more than half of these patients had previously suffered a myocardial infarction and undergone coronary artery bypass surgery, all had excellent ventricular function.

This factor may have partially accounted for the absence of acute clinical complications. It is of note that most patients had hypercholesterolemia and high blood pressure and that the low number of smokers in this series reflects the results of the nonsmoking laws and campaigns that take place in the United States. A recent study suggests that diabetes mellitus, multiple stents and a lower MLD after stenting could be the predictive factors of restenosis ${ }^{9}$. One of the main uses of LASER angioplasty is in treating long lesions ${ }^{7,8}$. The management of in-stent restenosis with balloon ${ }^{10,11}$, Simpson atherectomy catheter ${ }^{12,13}$, rotablator ${ }^{14-16}$ or with the placement of a new stent ${ }^{17,18}$, although effective and relatively safe, has been disappointing. The late permeability after treatment with the above-mentioned devices relates to a rate of restenosis of approximately $40 \%$ by the $6^{\text {th }}$ month of follow-up. In-stent restenosis presents as a long lesion, because the endothelial neoformation lines the entire internal surface of the stent, and is exacerbated by multiple stenting ${ }^{19-21}$. The ability of the LASER in performing tissue ablation has been previously shown in long lesions ${ }^{7,8}$. The studies of treatment of in-stent restenosis with LASER are limited. In a study of 7 cases, the procedure was considered effective and safe, and intracoronary monitoring with ultrasound showed that the LASER does not reach the stent ${ }^{20}$. In a recent retrospective nonrandomized study ${ }^{22}$, the procedure was $98 \%$ successful, with a mortality rate of $2 \%$ and a rate of emergency surgery of $11 \%$. The new restenosis rate at 6 months was $21 \%$ for laser + balloon and $38 \%$ for the balloon. Our study assesses patients with in-stent restenosis treated with laser + balloon. The procedure was $100 \%$ successful and the LASER was $71 \%$ successful. At 6 months, the rate of new restenosis was $24.2 \%$, and the rate of a new procedure in the target vessel (including a patient who underwent emergency surgery) was $27.3 \%$. One patient died from a noncardiac cause. It is of note that the results in this subgroup, although a smaller sample, are similar to the previously mentioned series. The rates of new restenosis in the present study may also be related to the diameter of the vessels treated, as $89.7 \%$ had a diameter $\geq 3.5 \mathrm{~mm}$. Similarly, it is not known if the rate of new restenosis at 6 months will remain the same as at 12 months, or if it will increase, considering the effect of the stent, a foreign bo$\mathrm{dy}$, within the vessel. Later, the rate of new restenosis was shown to increase from $24.2 \%$ to $27.3 \%$, and the rate of a new procedure in the vessel (including angioplasty and surgery) being required was slightly increased between 6 and 12 months of follow-up. Similarly, the rate of AMI, as well as the mortality rate, remained unchanged.

Therefore, we conclude that the LASER is safe and effective in the treatment of in-stent restenosis. The values of the clinical variables favor the LASER during the first 6 months of follow-up as compared with the results found in the literature about patients treated only with the balloon. There was a slight increase in the number of new procedures performed in the vessel treated with LASER + balloon between 6 and 12 months of follow-up. Finally, a randomized study comparing LASER versus balloon would be required to assess if the LASER has more advantages than the balloon in treating in-stent new restenosis. Although feasible, conducting a randomized study seems unlikely in the near future, considering the fact that studies with intracoronary radiation are beginning to be conducted.

Limitations of the study - In spite of the small sample size, each case was carefully assessed under a strict protocol. Although this was not a randomized study, as already mentioned, we assessed the first 33 reports of patients with in-stent restenosis, treated with LASER. At the Miami Heart Institute, most patients with in-stent restenosis are treated with LASER. 


\section{References}

1. Serruys PW, de Jaegere P, KiemeneijF, et al. A comparison of balloon-expandablestent implantation with balloon angioplasty in patients with coronary artery disease: BENESTENT Study. N Engl J Med 1994; 331: 489-95.

2. Fishman DL, Leon MB, Baim DS, et al. A randomized comparison of coronary-stent placement and balloon angioplasty in the treatment of coronary artery disease: Stent Restenosis Study Investigators. N Engl J Med 1994; 331: 496-501.

3. Schatz RA, Baim DS, Leon M, et al. Clinical experience with the Palmaz-Schatz coronary stent: initial results of a multicenter study. Circulation 1991; 83: 148-61.

4. Schomig A, Kastrati A, Mudra H, et al. Four-year experience with Palmaz-Schatz stenting in coronary angioplasty complicated by dissection with threatened or present vessel closure. Circulation 1994; 90: 2716-24.

5. Ellis SG, Savage M, Fischman D, Leon M, Goldberg S, Hirshfeld JW. Restenosis after placement of Palmaz-Schatz stents in native coronary arteries: Initial results of a multicenter experience. Circulation

6. Carrozza JPJ, Kuntz RE, Fishman RF, et al. Angiographic and clinical outcome of intracoronary stenting; Acute and long-term results from a large single-center experience. J Am Coll Cardiol 1992; 20: 328-37.

7. Bejarano J, Margolis J. Nuevas técnicas de intervención coronaria en pacientes de edad avanzada con cardiopatia isquemica grave: La experiencia de Miami. Guest Editors. Cardiol Intercont 1995; 4: 116-26.

8. Bittl J, Sanborn T, Tcheng J, Siegel R, Ellis S for the PELCA Registry. Clinical success, complications, and restenosis rates with excimer laser coronary angioplasty. Am J Cardiol 1992; 70: 1533-9.

9. Kastrati A, Schomig A, Elezi S, et al. Predictive factors of restenosis after stent placement. J Am Coll Cardiol 1997; 30: 1428-36.

10. Reimers B, Moussa I, Akiyama T, et al. Long-term clinical follow-up after successful repeat percutaneous intervention for stent restenosis. J Am Coll Cardiol 1997; 30: 186-92.

11. Eltchaninoff H, Cribier A, Koning R, et al. Balloon angioplasty for in-stent restenosis 6 months angiographic follow-up: Circulation 1997; 96(suppl I): I483.
12. Strauss BH, Umans VA, van Suylan RJ, et al. Directional atherectomy for treatment within coronary stents: clinical, angiographic and histologic results. J Am Coll Cardiol 1992; 20: 1465-73.

13. Bowerman RE, Pinkerton CA, Kirk B, et al. Disruption of a coronary stent during atherectomy for restenosis. Cathet Cardiovasc Diagn 1991; 24: 248-51.

14. Stone GW. Rotational atherectomy for treatment of in-stent restenosis: role of intracoronary ultrasound guidance. Cathet Cardiovasc Diagn 1996; 37 (suppl 3): 73-7.

15. SL Goldberg, T. Shawl, M. Buchbinder, et al. Rotational atherectomy for in-stent restenosis: The Baraster Registry. Circulation 1997; 96(suppl I): I 438.

16. Sharma, S, Duvvuri S, Kini A, et al. Rotational atherectomy for in-stent restenosis: Acute and long-term results of first 100 cases. J Am Coll Cardiol 1996; I-80(suppl I): 482.

17. Goldberg SL, Loussararian AH, et al. Stenting for In-Stent Restenosis. Circulation 1997; 96(suppl I): I 484.

18. Elezi S, Kastrati A, Herzzentrum D, et al. Stenting for restenosis of stented lesions: Acute and 6 months clinical and angiographic follow-up. J Am Coll Cardiol 1996, I-80(suppl I): 480

19. Hoffman GS, Mintz GR, Dussaillant, et al. Patterns and mechanism of in- stent restenosis, a serial intravascular ultrasound study. Circulation 1996; 94: 1254-67.

20. Haude M, Erbel R, Straub U, et al. Short and long term results after intracoronary stenting in human coronary arteries: monocentre experience with the balloon expandable Palmaz-Schatz stent. Br Heart J 1991; 66: 337-45.

21. Gordon PC, Gibson CM, et al. Mechanism of restenosis and redilation within coronary stents: quantitative angiographic assessment. J Am Coll Cardiol 1993; $21:$ 1166-74.

22. Mehran R, Mintz G, Satler L, et al. Treatment of in-stent restenosis with excimer laser coronary angioplasty: mechanisms and results compared with PTCA alone. Circulation 1997; 96: 2183-9. 